\title{
Foreword of the CIP papers
}

The CIP - 2003 was held in Antibes from June 30th to July 3th with 130 participants, half of them from France. The other Europe countries were in the order Germany, Belgium, Czech. Rep. and Switzerland.

The conference program was organized with Invited conferences, oral and poster presentations in two parallel sessions and three forums in full sessions.

The invited lectures were given as follows:

- E. Di Fabrizio (Trieste) Nanotechnology for interdisciplinary research

- S. Veprek (Garching) Superhard nanocomposites: design concept, properties, present and futur industrial apllications

- M.P. Delplancke (Bruxelles) Ultra-hard DLC-basd coatings

- R. Foerch (Mainz) Pulsed plasma polymerisation of thin organic films as supports for bio-molecules

- F. Rossi (Ispra) Modification of polymeric films for protein adhesion

- C. Heau (St-Étienne) Thin film deposition by magnetron sputtering

- K.P. Giapis (Pasadena) Scattering dynamics and mechanisms of etching reactions

- L. Lemos Alves (Lisboa) Fluid description of the energy absorption in microwave plasmas

- M. Laroussi (Newports News) Mechanisms of inactivation of bacteria by air plasma

- L. Sansonnens (Lausanne) Challenges in RF plasma deposition on square - meter substrates

- S. Pasquiers (Orsay) Removal of pollutants by plasma catalytic processes

- E. Fisher (Fort Collins) Understanding the mechanismsof plasma processing by exploring the chemistry of the plasma-surface interface.

The three CIP forums were organized in full sessions:

- Nano-miniaturisation with O. Joubert (LTM) as moderator. The activity of the CNRS network was presented by C. Gourgon, A. Pepin, C. Vieu and P. Chabert. It was followed by open discussions.

- Sterilisation with G. Legeay (Le Mans) and M. Moisan (Montreal) as moderators.

Before a free discussion, three short presentations were given by P. Koulik (APIT), M. Destrez (Absys) on the plasma sterilisation at the atmospheric pressure and by W. Zorzi (Liege) on the prions detection and decontamination.

- New trends of hard coatings with C. Donnet (St-Étienne) as moderator. The forum started with short presentations of C. Heau (HEF), A. Mattews (Hull), P. Kapsa (Lyon) and M. Benmalek (Pechiney) and was followed by free discussions.

Still this year the plasma sterilisation remained a hot subject. The sterilisation forum was followed by a meeting of the CRIN-PISE club at the evening of July 1st. Three presentations were given by M. Laroussi (Newports News), M. Sixou (Toulouse) and W. Zorzi (Liege).

Twelve presentations of the CIP (4 invited and 8 sollicited papers) have been revewed with the standard rules of EPJ-AP. They are published following two packages: the first one of 6 publications in the present volume and the second one, also of 6 publications, at the end of this year. 